\title{
BIOASSAY-GUIDED FRACTIONATION AND CHARACTERIZATION OF A BIOACTIVE ANTI-DIABETIC PRINCIPLE IN GNETUM AFRICANUM (WELW) METHANOL LEAF EXTRACT
}

\author{
Nkeiruka E Udeh¹, Anaga O Aruh², Isaac U Asuzu² \\ ${ }^{I}$ Veterinary Biochemistry and Animal production, Michael Okpara University of Agriculture, Umudike, Nigeria, \\ ${ }^{2}$ University of Nigeria, Nsukka, Nigeria
}

BACKGROUND: Gnetum africanum (Welw) is a green leafy plant predominantly found in West Africa and used in management of diabetes mellitus. However, its bioactive antidiabetic principle has hitherto, neither been identified nor isolated. This study was conducted to identify, isolate and characterize the bioactive antidiabetic principle in the plant using bioassay guided fractionation as well as nuclear magnetic resonance (NMR) spectroscopy.

METHODS: Gnetum africanum leaves were collected and identified by a plant taxonomist; air-dried and pulverized. The plant material was extracted in $80 \%$ methanol, concentrated in vacou and stored as Gnetum africanum methanol extract (GAE). Percentage yield was determined. The extract was tested for the presence of various phytochemicals using spot tests. Ten grammes of GAE was fractionated using glass column chromatography. Fractions collected were concentrated in vacou and tested for antidiabetic activity on alloxan-induced diabetic rats. The fraction with the highest percentage reduction in fasting blood sugar (FBS) was further fractionated using preparatory thin layer chromatography. The different bands, corresponding to different compounds were recovered and tested for antidiabetic activity. The compound with the highest reduction in FBS was subjected to liquid chromatography tandem electrospray ionization to determine the molecular mass, as well as NMR spectroscopy for characterization.

RESULTS: Percentage yield of GAE was $10.3 \mathrm{w} / \mathrm{w}$. Flavonoids, alkaloids and saponins were detected in GAE. Fractionation of the crude extract using column chromatography yielded 10 fractions. Fraction 7 gave the highest percentage reduction in FBS of 42.34 at the 6th hour. After the purification, 5 sub-fractions (GAF 7.1-7.5) were obtained. Sub-fractions 1, 2 and 4 produced 68, 78 and $71.4 \%$ reduction in FBS at the 6th hour respectively. Sub-fractions 1 and 2 had more than one peak on LC/ESI-MS while GAF7.4 had a single peak corresponding to a pure compound (291.2760 $\mathrm{g} / \mathrm{mol}$ ). This was subjected to NMR spectroscopy and the compound was found to be -(-)epicatechin, (Fig. 1).

Figure 1: Structure of Compound GAF7.4 (2R, 3R)-2-(3, 4-dihydroxyphenyl)-3, 4-dihydro-2H-chromene-3, 5, 7-triol CONCLUSIONS. Bioassay-guided fractionation revealed the presence of a (-)-epicatechin, a flavonoid. Further studies to determine the mechanism of action of this bioactive principle is highly recommended. 